\title{
COMPOSITIONS AND CHEMICAL BONDING IN CERAMICS BY QUANTTTATTVE ELECTRON ENERGY-LOSS SPECTROMETRY
}

\author{
J. BENTLEY, L.L. HORTON. C.J. McHARGUE. † S. McKERNAN,* C.B. CARTER,* \\ A. REVCOLEVSCHI, ${ }^{\ddagger}$ S. TANAKA, and R.F. DAVIS \\ Metals and Ceramics Division, Oak Ridge National Laboratory, PO Box 2008. Oak Ridge, \\ TN 37831-6376 ( ${ }^{\dagger}$ Now at: The University of Tennessee, Knoxville, TN 37993) \\ * Department of Chemical Engineering and Materials Science, University of Minnesota, \\ 421 Washington Ave. SE, Minneapolis, MN 55455-0132 \\ ‡ Laboratoire de Chimie des Solides, CNRS UA 446, Université Paris-Sud. Batiment 414. \\ 91405 Orsay Cedex, France. \\ Department of Materiais Science and Engineering, North Carolina State University, PO Box 7907, \\ Raleigh, NC 27695-7907.
}

\begin{abstract}
Quantitative electron energy-loss spectrometry was applied to a range of ceramic materials at a spatial resolution of $<5 \mathrm{~nm}$. Analysis of $\mathrm{Fe}_{\mathrm{L}_{3}}$ white lines indicated a low-spin state with a charge transfer of -1.5 electrons/atom onto the $\mathrm{Fe}$ atoms implanted into (amorphized) silicon carbide. Gradients of 2 to $5 \%$ in the $\mathrm{Co}: \mathrm{O}$ stoichiometry were measured across 100 -nm-thick $\mathrm{Co}_{3} \mathrm{O}_{4}$ layers in an oxidized directionally solidified $\mathrm{CoO}-\mathrm{ZrO}_{2}$ eutectic, with the highest $\mathrm{O}$ levels near the $\mathrm{ZrO}_{2}$. The energy-loss near-edge structures were dramatically different tor the two cobalt oxides: those for $\mathrm{Co}_{3} \mathrm{O}_{4}$ have been incorrectly ascribed to $\mathrm{COO}$ in the published literature. Kinetically stabilized solid solubility occurred in an AIN-SiC film grown by low-temperature molecular beam epitaxy (MBE) on $\alpha(6 \mathrm{H})-\mathrm{SiC}$, and no detectable interdiffusion occurred in couples of MBE-grown AIN on SiC following annealing at up to $1750^{\circ} \mathrm{C}$. In diffusion couples of polycrystalline $\mathrm{AlN}$ on $\mathrm{SiC}$, interfacial $8 \mathrm{H}$ sialon (aluminum oxy-nitride) and pockets of $\mathrm{Si}_{3} \mathrm{~N}_{4}$-rich $\beta^{\prime}$ sialon in the $\mathrm{SiC}$ were detected.
\end{abstract}

\section{INTRODUCTION}

Applications of electron energy-loss spectrometry (EELS) to ceramics have clearly demonstrated the powerfulness of this transmission electron microscopy (TEM) technique for characterization of such materials, especially those containing elements with atomic number $Z<10 .{ }^{1}$ Examples described here illustrate the sensitivity, accuracy, and limitations of quantitative composition determination and chemical bonding information when applied at a spatial resolution of $<5 \mathrm{~nm}$ to silicon carbide implanted with iron, to an oxidized directionally solidified $\mathrm{CoO}-\mathrm{ZrO}_{2}$ eutectic, and to aluminum nitride - silicon carbide diffusion couples.

\section{EXPERIMENTAL}

Analytical electron microscopy (AEM) was performed at ORNL with a Philips EM400T AEM equipped with a field emission gun (FEG), a Gatan 666 parallel-detection electron energy-loss spectrometer (PEELS) system, and an EDAX 9100 energy dispersive X-ray spectrometer (EDS). Philips CM12/STEM and CM30/STEM AEMs were also used. For microanalysis, specimens were usually cooled to $-130^{\circ} \mathrm{C}$ in Gatan double-tilt cooling holders. High-spatial-resolution PEELS data were acquired in the scanning TEM (STEM) mode with probes of $-2-\mathrm{nm}$ diameter (FWTM) containing $-0.8 \mathrm{nA}$, and incident and collection half-angles of 8 and 19 (or 30) mrad, respectively. Spectra were also recorded in the TEM mode with probe currents $>3 \mathrm{nA}$, an incident beam divergence of $3 \mathrm{mrad}$. and probes of $\leq 10-\mathrm{nm}$ diameter.

Polished single crystal $\alpha-\mathrm{SiC}$ platelets (Carborundum Company. Niagara Falls, NY) of predominately the $6 \mathrm{H}$ polytype, with the broad face parallel to the basal $(0001)$ plane, were implanted at room temperature with $160 \mathrm{keV}{ }^{57} \mathrm{Fe}$ to a fluence of $6 \times 10^{16}$ ions $/ \mathrm{cm}^{2}$ at the ORNL Surface Modification and Characterization Facility. ${ }^{24}$

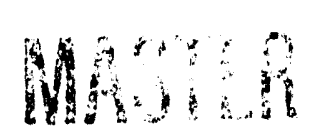

The submmed manuscriot has $D$ authored by a contractor of the rovernmem under contract No. ACO5-840R2 1400. Accordingity. the I Governmem retement a nonexctuen

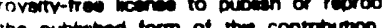
allow others to do so. for U.S. Goverm purposes. 
Directionally solidified cobalt oxide - zirconia eutectic material was grown at the Universite ParisSud by a floating zone melting technique, described previously. ${ }^{5}$

Three AIN-SiC materials, each having $\alpha(6 \mathrm{H})-\mathrm{SiC}$ single crystal substrates (Cree Research, Raleigh, $\mathrm{NC}$ ) oriented $3-4^{\circ}$ from [0001] toward [11 $\left.\overline{2} 0\right]$, were examined in cross section: (1) an AlN-SiC solid solution grown at $1050^{\circ} \mathrm{C}$ by plasma-assisted, gas-source molecular beam epitaxy (MBE); $;^{6}$ (2) diffusion couples of MBE-grown AIN on SiC annealed for $70 \mathrm{~h}$ at $1700^{\circ} \mathrm{C}$ or $25 \mathrm{~h}$ at $1850^{\circ} \mathrm{C}$; and (3) diffusion couples of polycrystalline sintered AlN (Dow Chemical) on the above specified SiC substrate, annealed at 1600 and $1700^{\circ} \mathrm{C}$.

Specimens were prepared for AEM by standard dimpling and ion milling techniques.

\section{IRON-IMPLANTED SILICON CARBIDE}

Silicon carbide ion-implanted with iron has been previously characterized by AEM. ${ }^{2-4}$ Implanted iron depth profiles were measured by EDS; no clustering of the iron in the amorphized SiC was detected by TEM. Information about the bonding of the iron was sought from examination of the electron energy-loss near-edge structure (ELNES) for the Fe $\mathrm{L}_{23}$ edge. Preliminary data ${ }^{24}$ have subsequently been supplemented and quantitatively analyzed. Figure 1 shows a comparison of the Fe $L_{23}$ ELNES in spectra measured with PEELS for a plan-view Fe-implanted SiC specimen sectioned to near the maximum Fe concentration (16 mol\%), and for various other iron-based materials. The spectra are normalized so that the level of excitation to the continuum states (say $E>735 \mathrm{eV}$ ), which is a good measure of the quantity of iron analyzed, is identical for all spectra. The white lines, which arise from transitions to unfilled $3 \mathrm{~d}$ levels, are much less intense for the Feimplanted $\mathrm{SiC}$ than for the other materials; they are also slightly broader. In more quantitative terms, Pearson et al. $^{7}$ have shown that the normalized white line intensity (WLI) ratio, relative to the intensity in a $50 \mathrm{eV}$ window, $50 \mathrm{eV}$ above the $\mathrm{L}_{3}$ edge (continuum states), can be used as a measure of the $3 \mathrm{~d}$ occupancy. Morrison et $\mathrm{al}^{8}{ }^{8}$ have derived expressions for measuring $3 \mathrm{~d}$ hole concentrations from $\mathrm{L}_{3}$ and $\mathrm{L}_{2}$ white line intensities. Clearly, the marked differences in the white lines in the spectra of Fig. 1 imply gross changes in the $3 \mathrm{~d}$ occupancies and thus of chemical bonding. Quantitative measurements of normalized WLI ratios ${ }^{7}$ for the spectra of Fig. 1 are shown in Table 1. The results imply a charge transfer of $>1.5$ electrons/atom onto the iron relative to metallic iron. Similarly, from the expressions of Morrison et al., ${ }^{8}$ the ratio of the number of $3 \mathrm{~d}$ holes for the implanted iron relative to that for metallic iron is 0.53 , again implying $\sim 1.4$ electrons/atom charge transfer. Additionally, the small $\mathrm{L}_{3} / \mathrm{L}_{2}$ WLI ratio for the implanted iron implies a low spin state; the ratio of $5 / 2$ to $3 / 2$ state holes for the implanted iron is $20 \%$ lower than for metallic iron. The results suggest that the iron in the $\mathrm{SiC}$ is not primarily metallically bonded and support the conclusion of earlier conversion electron Mossbauer spectroscopy data that the iron is in covalently bonded sites. ${ }^{9}$

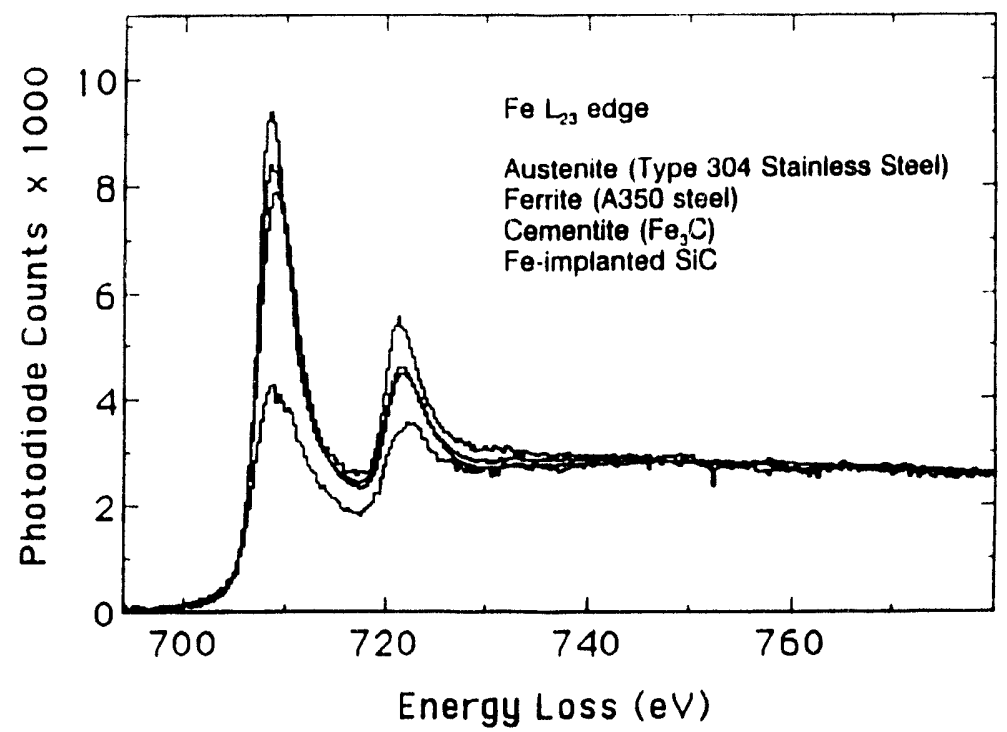

Table 1. Analysis of $\mathrm{Fe}_{2,3}$ white line intensities

\begin{tabular}{lcc}
\hline & $\begin{array}{c}\text { Normalized } \\
\text { WLI }\end{array}$ & $\begin{array}{c}\text { Implied 3d } \\
\text { occupancy }\end{array}$ \\
\hline $\mathrm{Fe}_{2} \mathrm{O}_{3}$ & 0.65 & 4.5 \\
$\mathrm{Fe}_{3} \mathrm{C}$ & 0.41 & 6.5 \\
Austenite & 0.42 & 6.3 \\
Ferrite & 0.37 & 6.9 \\
Fe in SiC & 0.20 & 8.6 \\
\hline
\end{tabular}

Fig. 1. Fe $\mathrm{L}_{23}$ ELNES for Austenite, ferrite, cementite, and Fe-implanted SiC. 


\section{COBALT OXIDE - ZIRCONIA EUTECTIC}

The morphology of directionally solidified eutectics (DSE) provides an excellent geometry for studying interfaces in materials, for example by high-resolution TEM. ${ }^{10}$ The thin, parallel plates which are formed in the $\mathrm{ZrO}_{2} / \mathrm{CoO}$ system also produce tlat interfaces on the microscopic scale. However, heat treatment of the eutectic in a high oxygen partial pressure results in a trilayer structure ${ }^{11,12}$ as the $\mathrm{CoO}$ transforms to $\mathrm{Co}_{3} \mathrm{O}_{4}$. The microstructure consists of alternating lamellae of $\mathrm{CoO}$ and calcium-stabilized cubic- $\mathrm{ZrO}_{2}$, each with widths of up to $1 \mu \mathrm{m}$, and a thin (100 to 200 $\mathrm{nm}$ ), irregular layer of $\mathrm{Co}_{3} \mathrm{O}_{4}$ spinel extending into the $\mathrm{CoO}$ from the flat $\mathrm{ZrO}_{2}$ interface. The growth direction of the DSE is [001 $]_{\mathrm{ZrO}} / /[1 \mathrm{TO}]_{\mathrm{COO}}$ and the broad interface is $(100)_{\mathrm{Z} O 2} / /(111)_{\mathrm{COO}}$. The $\mathrm{CO}_{3} \mathrm{O}_{4}$ is oriented cube-on-cube with the $\mathrm{CoO}$.

Typical core-loss PEELS data for the stabilized cubic zirconia phase are shown in Fig. 2a. The proximity of the $\mathrm{Zr} \mathrm{M}$ and overlap with the $\mathrm{Zr} \mathrm{M}$ preclude accurate use of the Ca $\mathrm{L}_{23}$ edge for composition determination but, fortunately, $\mathrm{Ca} / \mathrm{Zr}$ ratios are easily obtained by EDS. Such measurements indicate that the $\mathrm{Ca} / \mathrm{Zr}$ atomic ratio is 0.18 . However, for other aspects of composition determination, secondary excitation ${ }^{13}$ in EDS gives misleading results, such as the apparent presence of zirconium in the cobalt oxides and higher than actual levels of cobalt in the zirconia. Also, strong $\mathrm{X}$-ray absorption limits the accuracy of oxygen contents from EDS data.

Typical core-loss PEELS data for the cobalt oxide phases are shown in Fig. 2b. To determine compositions accurately, ${ }^{14}$ care has to be taken in the treatment of the energy-loss near-edge structure (ELNES), e.g., the Co $\mathrm{L}_{23}$ "white lines." A simple approach, that of beginning the integration window just beyond the most pronounced ELNES was used. The measured values of composition depend upon the position of the integration window and the use of the white line correction in the Gatan EL/P (version 2.1) software. A $100 \mathrm{eV}$ integration window offset from the edge threshold by $25 \mathrm{eV}$ gave the most reliable results. Further work, at higher spatial resolution, indicated a reproducible 2 to $5 \%$ gradient in the $\mathrm{Co}: \mathrm{O}$ ratio across the $\mathrm{Co}_{3} \mathrm{O}_{4}$ phase, with the lowest values (highest oxygen content) near the $\mathrm{ZrO}_{2}$ interface. This is consistent with the proposed mechanism of phase formation that is based on rapid diffusion of oxygen in the $\mathrm{ZrO}_{2}$ lamellae and slower lateral diffusion into the cobalt oxide. ${ }^{5}$ The measurement of such composition gradients is possible because the precision of the data is much better than the absolute accuracy.

Inspection of the oxygen energy-loss near-edge structure (ELNES) reveals dramatic differences between the $\mathrm{CoO}$ and $\mathrm{CO}_{3} \mathrm{O}_{4}$ (Fig. 3a). Interpretation of such oxygen ELNES is complex and involves consideration of site symmetry and states arising from hybridization of oxygen $2 p$ levels with metal $3 \mathrm{~d}$ and $4 \mathrm{~s}$ or $4 \mathrm{p}$ levels. ${ }^{15}$ Nevertheless, the differences in oxygen ELNES provide easily identifiable signatures for the two cobalt oxides. The cobalt $L_{23}$ white line ELNES (Fig. 3b) is superficially similar for the two phases, but there is a small shift to higher energies for the $\mathrm{Co}_{3} \mathrm{O}_{4}$ $\left(-1.5 \mathrm{eV}\right.$ for $\mathrm{L}_{3},-0.6 \mathrm{eV}$ for $\left.\mathrm{L}_{2}\right)$. The normalized WLI ratio, relative to the continuum states in a $50 \mathrm{eV}$ window, $50 \mathrm{eV}$ above the $\mathrm{L}_{3}$ edge ${ }^{7}$ is $0.53 \pm 0.02$ for the two cobalt oxides, implying similar 3 d occupancies. The $\mathrm{L}_{3} / \mathrm{L}_{2}$ WLI ratios are 3.88 and 2.58 for the $\mathrm{CoO}$ and $\mathrm{Co}_{3} \mathrm{O}_{4}$, respectively. From the type of analysis employed by Morrison et al., ${ }^{8}$ the ratios of $5 / 2$ to $3 / 2$ state holes are 1.42 and 0.89 for $\mathrm{CoO}$ and $\mathrm{Co}_{3} \mathrm{O}_{4}$, respectively, and the ratio of the total number of $3 \mathrm{~d}$ holes in $\mathrm{CoO}$ to those in $\mathrm{Co}_{3} \mathrm{O}_{4}$ is 0.98 , in agreement with the normalized WLI ratio analysis. Quantitative measurements were
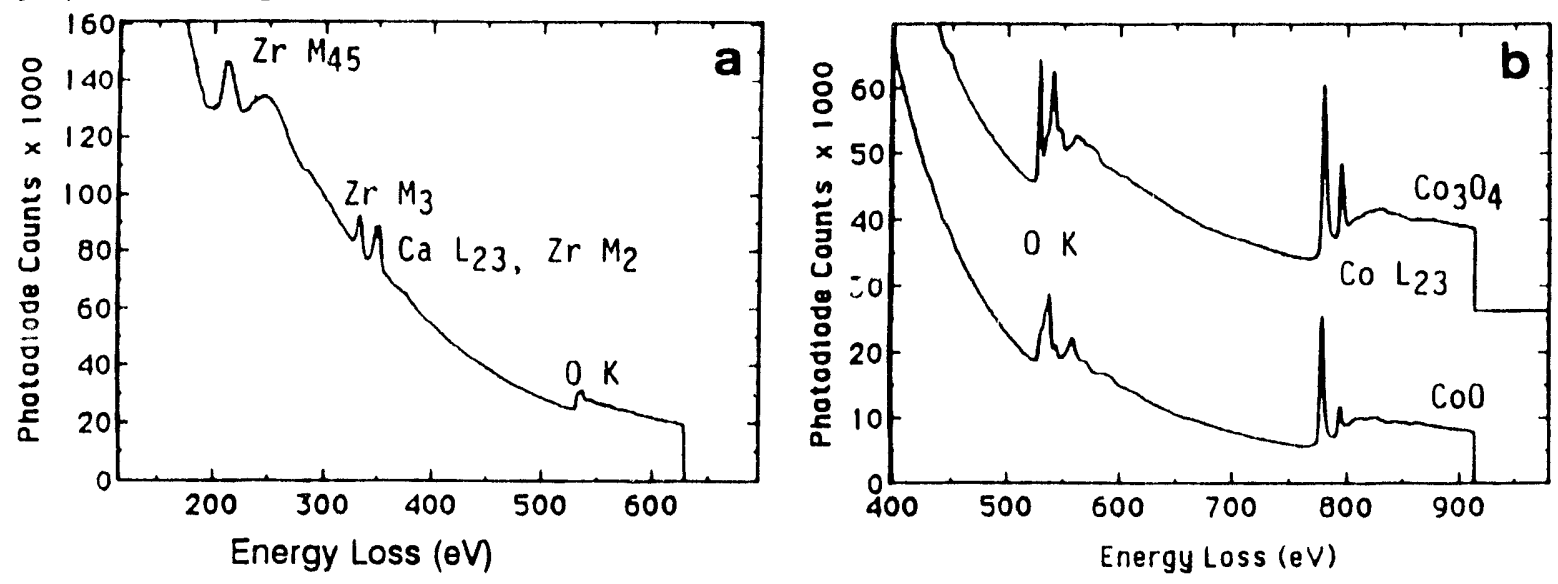

Fig. 2. Typical core-loss PEELS data for (a) $\mathrm{ZrO}_{2}(\mathrm{CaO})$, (b) $\mathrm{Co}_{3} \mathrm{O}_{4}$ and $\mathrm{CoO}$ phases. 

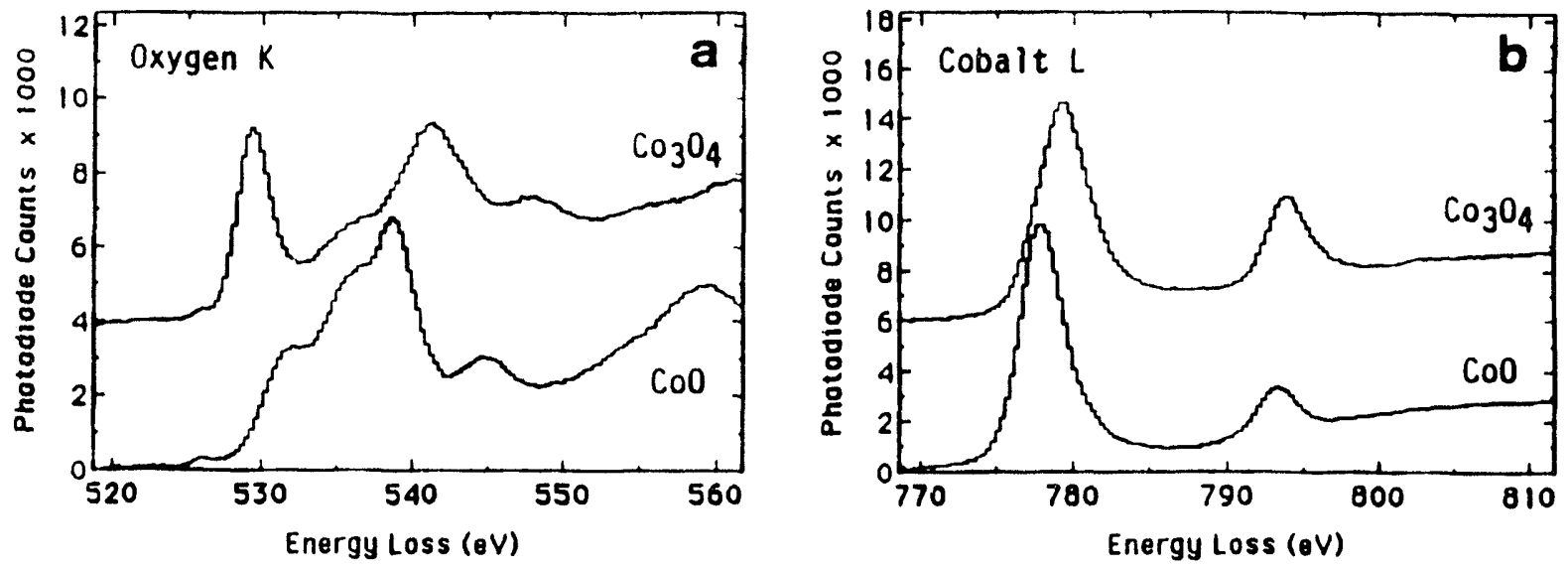

Fig. 3. (a) Oxygen $\mathrm{K}$ and (b) cobalt $\mathrm{L}_{23}$ ELNES for $\mathrm{CO}_{3} \mathrm{O}_{4}$ and $\mathrm{CoO}$ phases.

made on single scattering profiles, but difficulty was experienced in implementing even the simple geometric approach used by Pearson et al. ${ }^{7}$ because of the edge shape just beyond the white lines.

Oxygen and cobalt ELNES (with slightly better energy resolution than our present results) for cobalt oxide have recently been published. ${ }^{16}$ The results were stated as being for $\mathrm{CoO}$ that was made by oxidizing thin evaporated metal films in air at $400^{\circ} \mathrm{C}$. However, the published oxygen ELNES is not at all like our results for $\mathrm{CoO}$; instead, there is excellent agreement with our results for $\mathrm{CO}_{3} \mathrm{O}_{4}$. Similarly, the positions of the published $\mathrm{Co} \mathrm{L}$ white lines are more consistent with our data for $\mathrm{Co}_{3} \mathrm{O}_{4}$ than $\mathrm{CoO}$. Phase diagram data indicate that $\mathrm{Co}_{3} \mathrm{O}_{4}$ is the stable oxide below $-900^{\circ} \mathrm{C}$ for oxygen partial pressures of $>0.1 \mathrm{~atm}$. Kurata and Colliex ${ }^{17}$ have noted similar discrepancies for ELNES of $\mathrm{MnO}$ and $\mathrm{Mn}_{3} \mathrm{O}_{4}$.

Krivanek et al. ${ }^{18}$ extended the EDS-based ALCHEMI (atom location by channeling-enhanced microanalysis) method to demonstrate energy-loss with channeled electrons (ELCE) for $\mathrm{MgAl}_{2} \mathrm{O}_{4}$ spinel. Tafto and Krivanek ${ }^{19}$ further extended the method to demonstrate site-specific valence determination of $\mathrm{Fe}$ in a chromite spinel. Similar experiments were performed in an attempt to discriminate the signature of the di- and tri-valent cobalt ions in $\mathrm{Co}_{3} \mathrm{O}_{4}$, but no difference in the Co ELNES was detected. The most likely explanation for this behavior is that $\mathrm{Co}_{3} \mathrm{O}_{4}$ has the inverse spinel structure. ${ }^{12}$ There is some supporting evidence from $\mathrm{X}$-ray diffraction data on bond lengths; in addition, $\mathrm{Fe}_{3} \mathrm{O}_{4}$ has the inverse spinel structure. Further experiments are planned.

\section{ALUMINUM NITRIDE - SILICON CARBIDE}

Aluminum nitride and silicon carbide are structural ceramics and wide bandgap semiconductors which have similar hexagonal structures and a lattice mismatch in the basal plane of only $0.9 \%$. AlN$\mathrm{SiC}$ materiais are of interest as high temperature structural materials and as ceramic semiconductors for applications such as high power and ultraviolet optoelectronic devices, or for use in severe environments. The tentative AlN-SiC phase diagram of Zangvil and Ruh ${ }^{20}$ shows a flat miscibility gap at $-1950^{\circ} \mathrm{C}$ between -20 and $80 \% \mathrm{AlN}$, with a $2 \mathrm{H}$ solid solution above this temperature. The existence of the miscibility gap has been confirmed by several investigators (see Kern et al. ${ }^{6}$ ), notably Chen et al. ${ }^{21}$ Interdiffusion data exist only for $1950^{\circ} \mathrm{C}$ and higher. High resolution PEELS was used to detect possible interdiffusion at lower temperatures.

Examination of the AIN-SiC solid solution epilayer grown by $\mathrm{MBE}$ at $1050^{\circ} \mathrm{C}$ revealed predominantly the $2 \mathrm{H}$ polytype. Planar defects about $40 \mathrm{~nm}$ long and separated by about $5 \mathrm{~nm}$ in the growth direction were present on the basal planes. Their formation appears to be linked to the presence of similar sized steps on the growth surface, which are in turn related to the misorientation of the SiC substrate. ${ }^{2}$ No compositional inhomogeneity was detected by PEELS, the solid solution presumably being kinetically stabilized at the low growth temperature. Quantitative analysis of PEELS data indicated N/C and AJ/Si atomic ratios of $0.75 \pm 0.05$, in contrast to published ${ }^{6}$ Auger measurements of $\sim 0.43$.

Similarly, high spatial resolution PEELS failed to detect any interdiffusion in the diffusion couples of AIN grown by MBE on $\alpha(6 \mathrm{H})-\mathrm{SiC}$ and annealed at 1700 or $1850^{\circ} \mathrm{C}$, either near the substrate interface or at threading dislocations in the epilayer. Auger depth frofiles had indicated apparent 
substantial interdiffusion, but large growth-surface steps and concomitantly large variations in epilayer thickness (30\%), explain the misleading Auger results. ${ }^{22}$

In the diffusion couples of polycrystalline $\mathrm{AlN}$ on $\alpha(6 \mathrm{H})-\mathrm{SiC}$ annealed at 1600 and $1700^{\circ} \mathrm{C}$, an additional phase, typically $\leq 50$-nm-thick, was present at the SiC-AIN interface, but only where the AIN was epitactic to the SiC. Typical PEELS data from this phase are shown in Fig. 4 ; the major constituents are $\mathrm{N}, \mathrm{O}$, and $\mathrm{Al}$ : there is also a small $\mathrm{Si}$ signal. The $\mathrm{O} / \mathrm{N}$ ratio measured by PEELS ranged from 0.35 to 0.75 ; beam damage probably contributed to the variability. High-magnification images of the interface phase revealed a $2.3 \mathrm{~nm}$ periodicity along the c-axis. The interface phase was thus identified as the $8 \mathrm{H}$ sialon phase $\mathrm{e}^{23.24}$ which is based on the $8 \mathrm{H}$ aluminum oxynitride polytypoid of nominal composition (AlN) ${ }_{2} \mathrm{Al}_{2} \mathrm{O}_{3}{ }^{24}$ With EDS, secondary excitation of the SiC precludes confident identification of the small Si signal as intrinsic to the $8 \mathrm{H}$ interface phase; with PEELS there

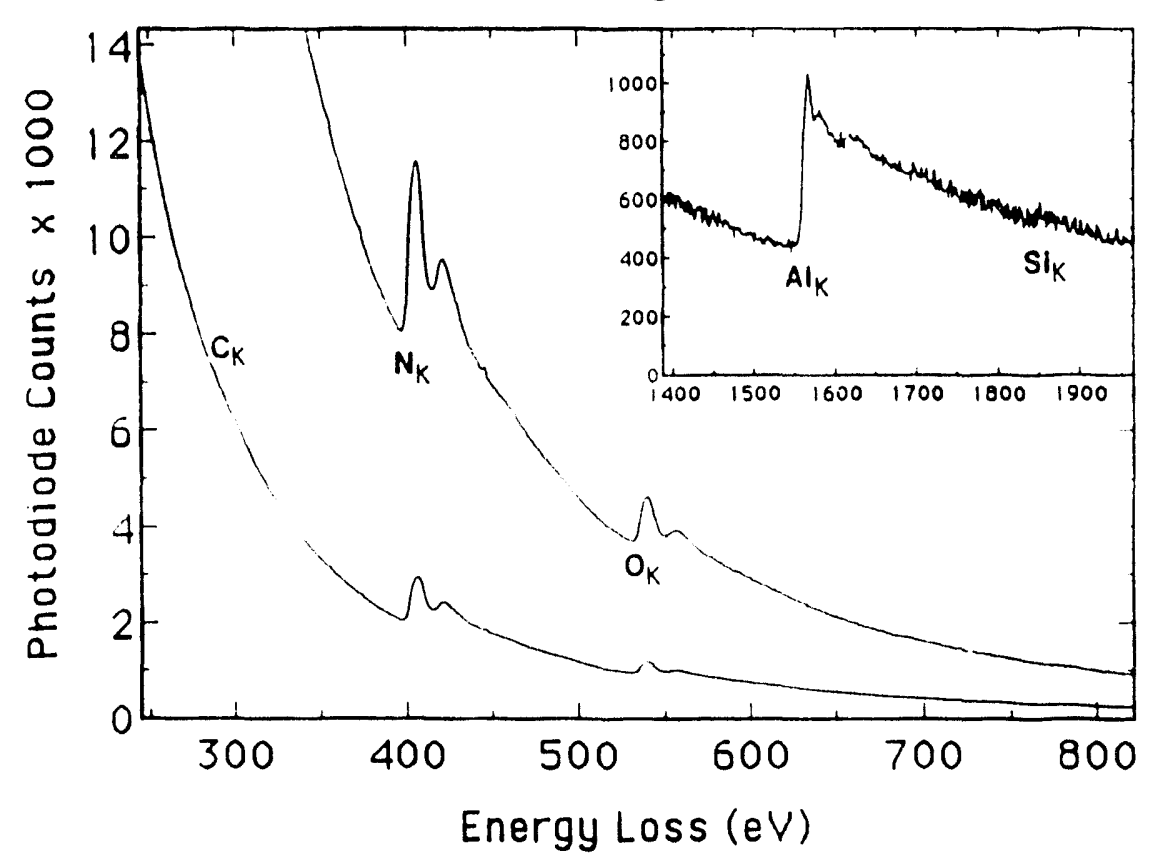

Fig. 4. PEELS data for $8 \mathrm{H}$ sialon interface phase.

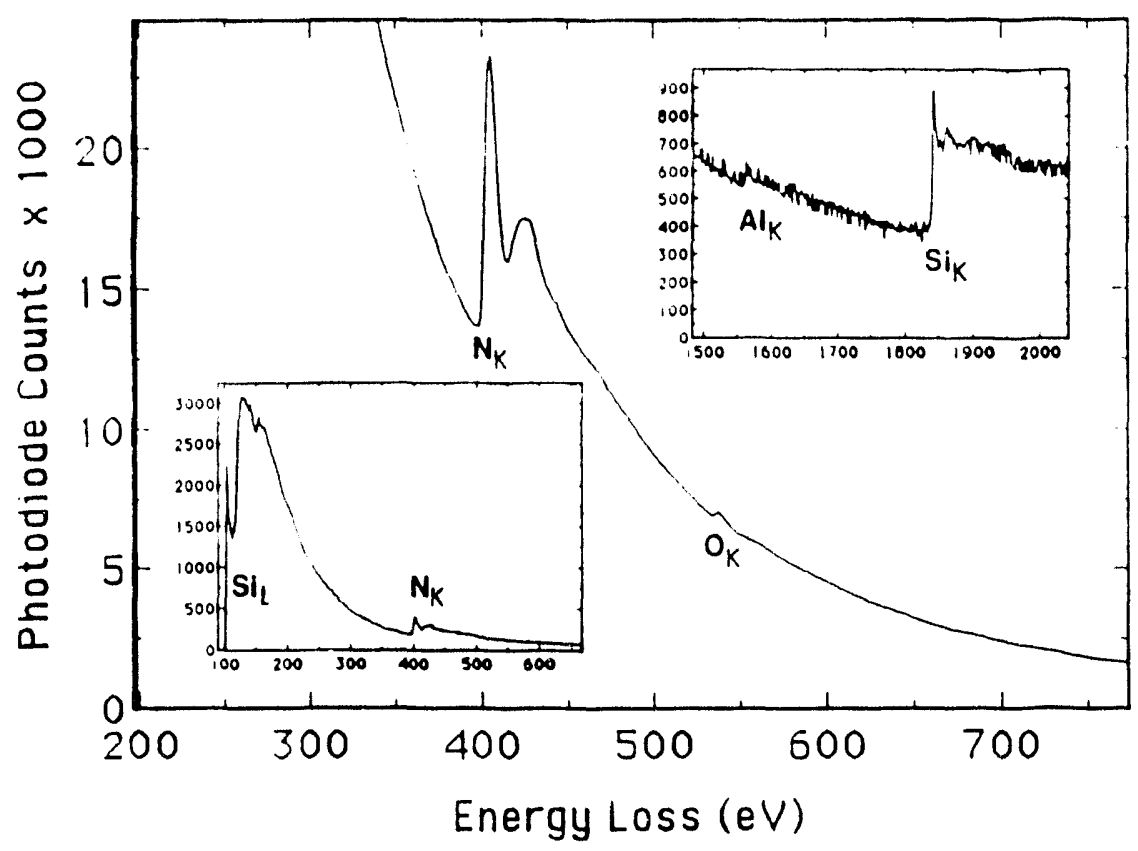

Fig. 5. PEELS data for $\mathrm{Si}_{3} \mathrm{~N}_{4}$-rich $\beta^{\prime}$ sialon particles. is no such concern. Sputtered films from the ion milling are also unlikely since no Si was detected by PEELS on the nearby AlN. The oxygen presumably originates as a surface impurity on the starting materials. The exact epitaxy of AIN grains with the SiC, strongly suggests recrystallization of AIN $(2 \mathrm{H})$ from the $8 \mathrm{H}$ sialon. Interestingly, this would mean that the dome defects, prevalent in the epitactically oriented grains, nucleate at the dome top, increase in diameter as the grain boundary advances, and eventually pinch off at the oxygen-rich basal fault.

No aluminum was detected in the SiC, even adjacent to the interface, but particles typically $250 \mathrm{~nm}$ in diameter, and occasionally up to $1 \mu \mathrm{m}$ long, form within the SiC at distances up to several micrometers from the $\mathrm{SiC}$ AlN interface. Quantitative analysis of typical PEELS data (Fig. 5) yields $\mathrm{Si}_{3} \mathrm{~N}_{4}$ with small levels of $O$ and Al. Diffraction patterns confirm the $\mathrm{Si}_{3} \mathrm{~N}_{4}$-rich $\boldsymbol{\beta}^{\prime}$ sialon identification and show $[0001]_{B}, / /[1120]_{6 \mathrm{H}}$ and $[10 \mathrm{~T} 0]_{,}, / /[0006]_{6 \mathrm{H}}$. Oxvgen is suspected of playing an important role in the precipitate Cormation. 


\section{CONCLUSIONS}

The results vividly illustrate the efficacy of PEELS for the microanalysis of ceramics. Some questions remain regarding the validity of the normalized WLI ratio method for $3 \mathrm{~d}$ occupancy measurement in 3d transition metal compounds. The method appeared useful for the $\mathrm{Fe}$ in amorphous $\mathrm{SiC}$, but less so for differentiating $\mathrm{Co}^{2+}$ and $\mathrm{Co}^{3+}$ in cobalt oxides. The ability to measure compositions by PEELS, particularly for elements with $\mathrm{Z}<10$, at a spatial resolution of a few nanometers is unmatched. The absence of secondary excitation processes, which can plague EDS measurements of multi-phase materiais, leads to greater confidence in the determined compositions. The Co:O stoichiometry gradients across the $100-\mathrm{nm}$-wide $\mathrm{CO}_{3} \mathrm{O}_{4}$, the absence of $\mathrm{AlN}$-SiC interdiffusion at low temperatures, and the importance of the minor constituents for sialon phase identification, are all examples where PEELS has clear advantages over any other technique.

\section{ACKNOWLEDGEMENTS}

This research was supported by the Division of Materials Sciences, U.S. Department of Energy under contract DE-AC05-84OR21400 with Martin Marietta Energy Systems, Inc. and through the SHaRE program under contract DE-AC05-76OR00033 with Oak Ridge Associated Universities, by NSF under grant \#DMR-8901218, and by the Office of Naval Research.

\section{REFERENCES}

1 J. Bentley, in Transmission EELS in Materials Science, edited by M.M. Disko, C.C. Ahn, and B. Fultz (The Minerals, Metals and Materials Society, Warrendale, PA, 1992), pp. 155-181.

2 J. Bentley, L.J. Romana, L. L. Horton, and C.J. McHargue in Phase Formation and Modification by Beam-Solid Interactions, edited by G.S. Was, L.E. Rehn, and D.M. Follstaedt (Mater. Res. Soc. Proc. 235, Pittsburgh, PA, 1992) pp. 363-368.

3 L.L. Horton, J. Bentley, L. Romana, A. Perez, C.J. McHargue, and J.C. McCallum, Nucl. Instr. and Meth. B65, 345-351 (1992).

4 J. Bentley, L.J. Romana, L.L. Horton, and C.J. McHargue, in Proc. 50th Ann. Meet. Electron Microscopy Soc. Amer., edited by G.W. Bailey, J. Bentley, and J.A. Small (San Francisco Press, San Francisco, 1992) pp. 346-7.

5 G. Dhalenne, F. d'Yvoire, P. Berthet, and A. Revcolevschi, Solid State Ionics 63-65, 396-400 (1993).

6 R.S. Kern, L.B. Rowland, S. Tanaka, and R.F. Davis, J. Mater. Res. 8 1477-80 (1993).

7 D.H. Pearson, B. Fultz, and C.C. Ahn, Appl. Phys. Lett. 53, 1405 (1988).

8 T.I. Morrison, M.N. Brodsky, N.J. Zaluzec, and L.R. Sill, Phys. Rev. B 32, 3107 (1988).

9 C.J. McHargue, A. Perez, and J.C. McCallum, Nucl. Inst. and Meth. B59/60, $1362-5$ (1991).

10 V.P. Dravid, C.E. Lyman, M.R. Notis, and A. Revcolevschi. Ultramicroscopy 29, 60-70 (1989).

11 J. Bentley, S. McKernan, C.B. Carter, and A. Revcolevschi, Microbeam Analysis 2 S286-7 (1993).

12 J. Bentley, S. McKernan, C.B. Carter, and A. Revcolevschi, in EMAG'93, edited by A.J. Craven (Institute of Physics, Bristol, UK, 1993), in press.

13 J. Bentley, P. Angelini, and P.S. Sklad, in Analytical Electron Microscopy 1984, edited by D.B. Williams and D.C. Joy (San Francisco Press, San Francisco, 1984) pp. 315-7.

14 R.F. Egerton, EELS in the Electron Microscope, (Plenum, New York. 1986).

15 F.M.F. de Groot, M. Grioni, J.C. Fuggle, J. Ghijsen, G.A. Sawatzky, and H. Petersen, Phys. Rev. B 40, 5715-23 (1989).

16 O.L. Krivanek and J.H. Paterson, Ultramicroscopy 32, 313-8 (1990).

17 H. Kurata and C. Colliex, Phys Rev. B 48, 2102-8 (1993).

18 O.L. Krivanek, M.M. Disko, J. Tafto, and J.C.H. Spence, Ultramicroscopy 9, 249-254 (1982).

19 J. Tafto and O.L. Krivanek, Phys. Rev. Lett. 48, 560 (1982).

20 A. Zangvil and R. Ruh, J. Am. Ceram. Soc. 71, 884 (1988).

21 J. Chen. Q. Tian, and A.V. Virkar, J. Am. Ceram. Soc. 75, 809-21 (1992).

22 J. Bentley, S. Tanaka, and R.F. Davis, in $E M A G$ '93, edited by A.J. Craven (Institute of Physics, Bristol, UK. 1993), in press.

23 K.H. Jack. J. Mater. Sci. 11, 1135-58 (1976).

24 J.W. McCauley et al., in Ceramic Microstructures '86, edited by J. Pask and A. Evans (Plenum, New York, 1988). 


\section{DISCLAIMER}

This report was prepared as an account of work sponsored by an agency of the United States Government. Neither the United States Government nor any agency thereof, nor any of their employees, makes any warranty, express or implied, or assumes any legal liability or responsibility for the accuracy, completeness, or usefulness of any information, apparatus, product, or process disclosed, or represents that its use would not infringe privately owned rights. Reference herein to any specific commercial product, process, or service by trade name, trademark, manufacturer, or otherwise does not necessarily constitute or imply its endorsement, recommendation, or favoring by the United States Government or any agency thereof. The views and opinions of authors expressed herein do not necessarily state or reflect those of the United States Government or any agency thereof. 

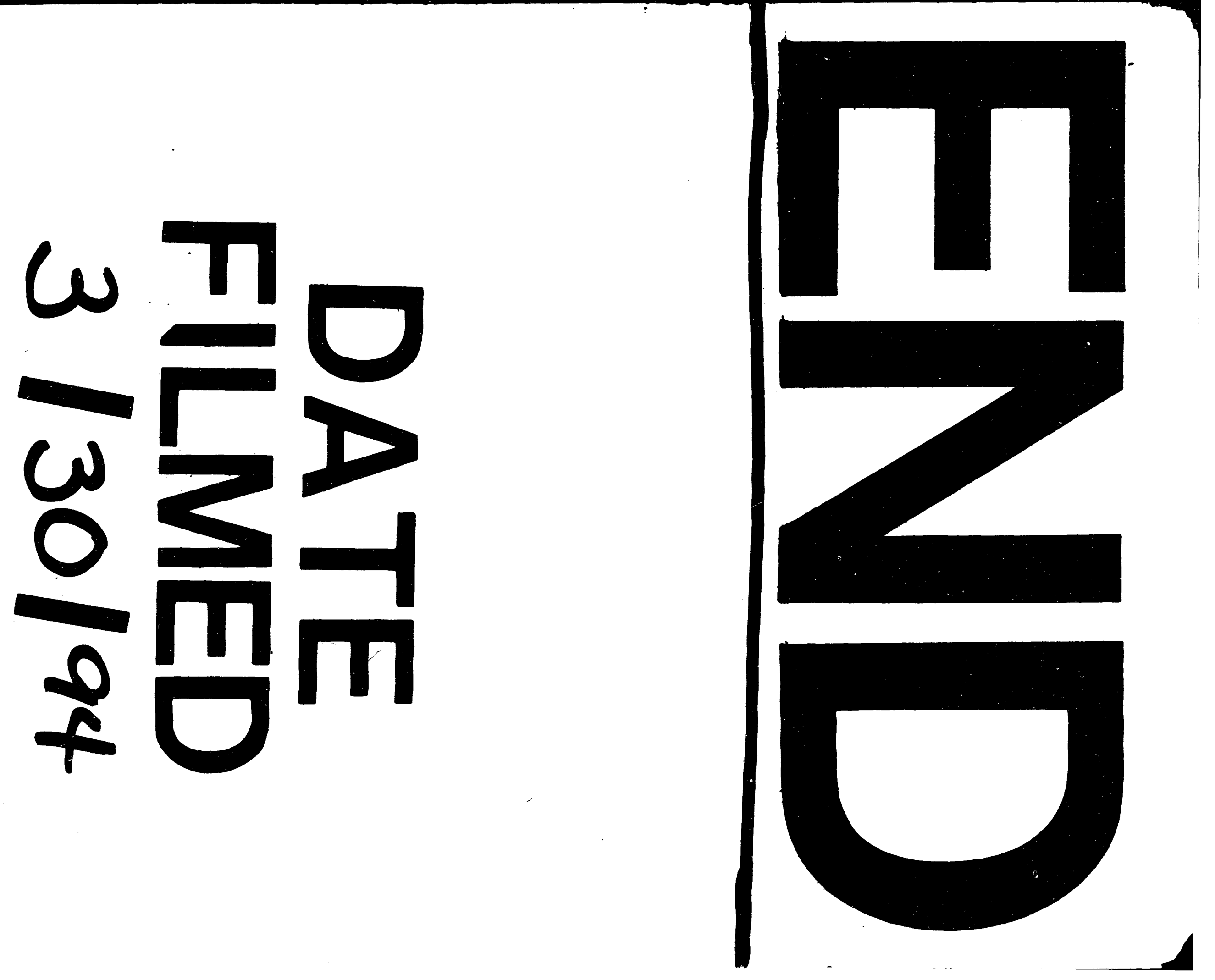
